\title{
Konseling Behavioral Berbasis Budaya Batak Angkola
}

\author{
Mukhtar Zarkasih Harahap ${ }^{1}$, Nur Hidayah ${ }^{1}$, M. Ramli ${ }^{1}$, Husni Hanafi ${ }^{1}$ \\ ${ }^{1}$ Bimbingan dan Konseling-Universitas Negeri Malang
}

\section{INFO ARTIKEL}

\section{Riwayat Artikel:}

Diterima: 31-05-2019

Disetujui: 17-02-2020

\section{Kata kunci:}

behavioral counselling;

batak angkola culture;

konseling behavioral;

budaya batak angkola

\section{ABSTRAK}

\begin{abstract}
Batak Angkola is an Indonesian cultural richness which located in Sumatra Island. Angkola Batak has different characteristics of cultural values. Culture is the mind, reason, results, customs and traditions that guide the behavior in human life. Each individual is a reflection of experience, namely the situation or stimulus that someone received. To understand the individual personality, it can be seen through the visible behavior. Behavioral Counseling is one of the counseling approaches which assume that wrong behavior resulting from wrong learning and education, both as a result of environmental influences and other social aspects. The purpose of Behavioral counseling containing Angkola Batak cultural values is to help the counselee high school students to get new behavior learned, including maladaptive behavior.
\end{abstract}

\begin{abstract}
Abstrak: Batak Angkola merupakan kekayaan budaya bangsa Indonesia yang terletak di kawasan Pulau Sumatera. Batak Angkola memiliki karekteristik nilai budaya yang berbeda. Budaya merupakan pikiran, akal budi, hasil, adat istiadat yang menjadi pedoman tingkah laku dalam kehidupan manusia. Setiap individu merupakan cerminan dari pengalaman, yaitu situasi atau stimilus yang diterimanya. Untuk memahami kepribadian individu tidak lain adalah dari perilakunya yang tampak. Konseling Behavioral merupakan salah satu pendekatan konseling yang berasusmsi bahwa perilaku yang salah akibat dari pembelajaran dan pendidikan yang salah, baik sebagai akibat dari pengaruh lingkungan maupun aspek sosial lainya. Tujuan konseling Behavioral berbasis nilai budaya Batak Angkola adalah membantu konseli siswa SMA untuk mendapatkan tingkah laku baru dengan dipelajari (learned), termasuk tingkah laku maladaptive (salah suai).
\end{abstract}

\section{Alamat Korespondensi:}

Mukhtar Zarkasih Harahap

Bimbingan dan Konseling

Universitas Negeri Malang

Jalan Semarang 5 Malang

E-mail: mukhtar.harahap.1601118@students.um.ac.id

Konseling merupakan salah satu layanan utama dalam membantu memandirikan siswa dalam penyelesaian masalah. Pelaksanaan kegiatan konseling, bukan merupakan kegiatan yang sederhana. Hal ini ditandai dengan kegagalan yang tidak jarang terjadi pada proses konseling sebagai akibat dari sifat kurang profesionalnya seorang konselor dalam menanggani permasalahan siswa. Peraturan menteri pendidikan dan kebudayaan nomor 111 tahun 2014 tentang bimbingan dan konseling pada pendidikan dasar dan menengah mendeskripsikan bimbingan dan konseling di sekolah merupakan suatu upaya sistematis, objektif, logis, dan berkelanjutan serta memiliki program yang dilakukan oleh guru bimbingan dan konseling/konselor sekolah untuk memfasilitasi perkembangan peserta didik/siswa dalam mencapai kemandirian, dengan wujud adanya kemampuan untuk memahami, menerima, mengarahkan, mengambil keputusan, serta merealisasikan diri secara baik juga memiliki rasa tanggung jawab dalam mencapai kebahagiaan dan kesejahteraan hidupnya. Salah satu layanan khusus yang membedakan bimbingan dan konseling dengan profesi lainnya adalah konseling individual.

Untuk mewujudkan proses konseling yang lancar, konselor harus mampu memahami unsur budaya konseli dalam memberikan layanan konseling. Hidayah (2017) menyebutkan untuk mampu berhasil dalam proses konseling, perlu diperhatikan beberapa faktor yang dinilai mampu memengaruhi keberhasilan konseling, antara lain kompetensi konselor dalam berkomunikasi; penguasaan konselor dalam menggunakan model konseling, kemampuan berpikir, serta nilai budaya yang didopsi oleh konselor. Beberapa model konseling tidak mampu mengakomodasikan nilai-nilai budaya dari masing masing siswa. Hasil lainnya atas penelitian Hidayah (2017) memberikan gambaran bahwa Indonesia turut perlu mengkaji variabel budaya dalam proses koseling yang diakukan mengingat Indonesia adalah Negara yang terdiri daru berbagai suku bangsa dan budaya. Hal ini sejalan dengan kode etik Asosiasi Bimbingan dan Konseling Indonesia bahwa konselor melayani konseli dengan berbagai macam latar belakang budayanya.

Saat ini muncul banyak penelitian untuk mengakomodasikan nilai budaya dalam model konseling. Senada dengan itu Hidayah (2017) dalam penelitiannya menjelaskan bahwa lahirnya model konseling berbasis budaya maupun kearifan lokal sangat diharapkan melihat permasalahan yang dialami peserta didik saat ini perlu diinternalisasi lagi nilai budaya sebagai karakter yang khas dan sesuai dengan ajaran nilai budaya siswa apapun latar belakang budayanya. Hidayah (2017) menyatakan 
bahwa konseling berbasis budaya merupakan layanan konseling untuk konseli agar terjadi perkembangan yang berdasarkan kualitas individu manusia sebagai pelaku dan pembentuk budaya. Secara sederhana dapat dikatakan, konseling berbasis budaya merupakan bentuk perlakuan konselor terhadap konseli melalui budayanya. Pendekatan tersebut mencoba mendekatkan konseli terhadap culture value system (sistem nilai budaya) agar mampu memahami diri, menerima diri, mengarahkan diri, dan mewujudkan diri dalam mencapai identitas kehidupannya yang bermakna.

Pada umumnya, terdapat beberapa model pendekatan konseling yang dapat digunakan dalam proses konseling individu, satu diantaranya adalah pendekatan konseling Behavioral. Konseling Behavioral yang berfokus pada perilaku turut dikembangkan lebih lanjut untuk mengakomodasi nilai-nilai budaya konseli. Konseling Behavioral merupakan salah satu model pendekatan konseling yang dapat digunakan dalam proses konseling individu, satu diantaranya adalah pendekatanberasusmsi bahwa perilaku yang salah akibat dari pembelajaran dan pendidikan yang salah, baik sebagai akibat dari pengaruh lingkungan maupun aspek sosial lainya. Tujuan konseling Behavioral menurut Corey (2017) adalah membantu konseli untuk mendapatkan tingkah laku baru. Dasar alasannya adalah bahwa segenap tingkah laku adalah dipelajari (learned), termasuk tingkah laku maladaptive (salah suai). Konseling Behavioral merupakan bentuk adaptasi dari aliran psikologi behavioristik yang menekankan perhatiannya pada perilaku yang tampak. Perbedaan sudut pandang tentang budaya barat dan budaya di Indonesia sedikit berbeda. Hidayah (2017) mengungkapkan pendekatan utama atau main-stream konseling Barat sudah dikembangkan dan teruji, serta diterapkan secara efektif terhadap konseli Barat dan oleh konselor Barat. Kondisi ini sangat sesuai untunk mengembangkan konseling Behavioral bermuatan budaya dengan kondisi yang ada di Indonesia yang memiliki banyak budaya.

Dalam kehidupan manusia tidak terlepas dari persoalan nilai. Nilai merupakan sifat atau hal-hal yang penting atau berguna bagi kehidupan manusia. Dengan akal budi, manusia mampu menciptakan kebudayaan. Indonesia dengan beribu suku tentu memiliki berjuta nilai-nilai positif yang dimiliki budaya-budayanya. Keberagaman budaya di Indonesia juga akan mengarhakan penentuan sumber nilai, harapan dan kebutuhan pada diri masyarakatnya yang khas (Hanafi, Hidayah, \& Mappiare, 2018). Salah satu budaya yang memiliki nilai-nilai positif dalam perilakunya adalah budaya Batak Angkola. Masyarakat Batak Angkola, adalah salah satu bagian dari sub suku Batak yang ada di Indonesia yang berada di kawasan pulau Sumatera. Batak Angkola yang mendiami wilayah induk Angkola (Padangsidimpuan), Padang Lawas Utara, Sipirok dan Batang Toru (Fitrah, 2008). Suku Batak Angkola yang memegang sistem kekerabatan berdasarkan prinsip dalihan natolu, yaitu pertautan tiga (tolu) unsur kekerabatan; kahanggi (teman semarga), anak boru (kelompok pengambil istri) dan mora (pihak pemberi istri). Adapun Marga di lingkungan suku Batak Angkola adalah Harahap, Siregar, Hasibuan, Batubara, Dasopang, Daulay, Dalimunthe, Rambe, Siagian, Ritonga dan Tanjung. Siahaan (1964) menyatakan bahwa sekalipun di rantau, suku Batak selalu peduli dengan identitas sukunya, seperti berusaha mendirikan perhimpunan semarga atau sekampung dengan tujuan untuk menghidupkan ide-ide adat budayanya.

Sebagai sebuah budaya, Batak Angkola memiliki nilai-nilai positif. Harahap (1987) mengungkapkan bahwa Batak Angkola mempunyai sembilan nilai budaya utama. Sembilan nilai budaya tersebut dituliskan secara berurutan, yaitu (1) Kekerabatan, masyarakat Batak Angkola sangat mengutamakan semangat kekerabatan, (2) Religi, masyarakat Batak Angkola sangat religius hal ini dapat dilihat dari bagaimana pelaksanaan adat tidak bertentangan dengan ajaran agama, (3) Hagabeon, masyarakat Batak Angkola selalu mengharapkan panjang umur dan banyak keturunan, (4) Hamajuon, masyarakat Batak Angkola memiliki semangat untuk menuntut ilmu baik salah satunya melalui upaya merantau, (5) Hasangapon, masyarakat Batak Angkola menjunjung tinggi untuk terpandang dan terhormat dalam masyarakat dengan menjaga nama baik keluarga dan marga, (6) Hamoraon, masyarakat Batak Angkola berpandangan bahwa dirinya harus memiliki keteladanan perilaku, kewibawaan, dan jiwa kepemimpinan , (7) Uhum merupakan nilai budaya yang membuat masyarakat Batak Angkola menjadi masyarakat yang menghargai tinggi kebenaran sekaligus peka terhadap ketidakberesan atau permasalahan, (8) Pengayoman, nilai pengayoman sudah tertera dalam interaksi kekerabatan dalihan natolu. Setiap orang Batak Angkola adalah pengayom dan yang diayomi, mora sebagai pengayom dan anak boru yang diayomi, dan (9) Konflik, bagi masyarakat Batak Angkola konflik adalah sebuah aib dan hal tersebut harus segera diselesaikan.

Paparan dan gagasan yang telah disampaikan menjadi dasar atas perlumya dilakukan penelitian pengembangan model pendekatan konseling Behavioral berbasis budaya Batak Angkola untuk dapat digunakan oleh para praktisi konseling yang ada di lapangan. Pendekatan konseling behavioral berbasis budaya Batak Angkola menekankan untuk mengubah perilaku salah dalam penyesuaian dengan cara memperkuat perilaku yang diharapkan, dan meniadakan perilaku yang tidak diharapkan serta membantu menemukan cara-cara berperilaku yang tepat sesuai dengan nilai-nilai yang ada dalam kehidupan masyarakat Batak Angkola. Penelitian dan pengembangan model pendekatan konseling Behavioral berbasis budaya Batak Angkola ini memiliki tujuan untuk pengembangan keilmuan Bimbingan dan Konseling dengan latar budaya yang beraneka ragam khususnya pada budaya Batak Angkola agar konselor dapat menjadikannya sebagai referensi untuk menambah wawasan dan sebagai alternatif dalam mengembangkan keterampilan konseling Behavioral bermuatan nilai budaya Batak Angkola.

\section{METODE}

Penelitian dan pengembangan ini menggunakan model Borg \& Gall (1983), dalam model ini terdapat sepuluh langkah pada penelitian dan pengembangan model Borg and Gall, yaitu (1) penelitian dan pengumpulan data, (2) perencanaan, (3) pengembangan draft produk, (4) uji coba lapangan awal, (5) merevisi hasil uji coba, (6) uji coba lapangan, (7) penyempurnaan produk hasil uji coba lapangan, (8) uji pelaksanaan lapangan, (9) penyempurnaan produk akhir, (10) desiminasi dan 
implementasi. Pengembangan model konseling Behavioral berbasis nilai budaya Batak Angkola ini menggunakan penelitian pengembangan Borg and Gall berdasarkan pertimbangan (1) langkah penelitian dan pengembangan dalam model ini bersifat sistematis, (2) terdapat relevansi antara tujuan penelitian dengan model penelitian dan pengembangan yang digunakan, (3) sasaran produk merupakan invidu dengan kondisi psikologis sehingga perlu dilakukan uji kelayakan demi validitas produk, dan (4) penelitian didasarkan pada studi pendahuluan dan studi literatur sehingga memberikan kontribusi kepada kebergunaan produk pengembangan yang akan dihasilkan.

Instrumen penilaian yang digunakan pada penelitian dan pengembangan ini adalah skala penilaian model skala likert dengan empat alternatif pilihan jawaban. Skala penilaian ini untuk mengetahui ketepatan dan kelayakan produk panduan konseling Behavioral berbasis Budaya Batak Angkola ini dapat diterima. Teknik analisis data menggunakan Rater Agreement, (Gregory, 2011).

\section{HASIL}

Penelitian pengembangan ini menghasilkan produk berupa buku panduan konseling Behavioral berbasis budaya Batak Angkola. Validasi keberterimaan (akseptabilitas) produk pengembangan ini dilakukan dengan cara uji ahli (expert judgement). Uji ahli keberterimaan dan kelayakan produk pengembangan ini memberikan hasil, antara lain (1) kelayakan format panduan untuk mengetahui kejelasan penulisan dan kemenarikan desain panduan oleh ahli media pembelajaran, (2) kelayakan isi materikonseling dalam buku panduan oleh ahli bimbingan dan konseling pembelajaran, (3) kelayakan isi muatan nilai budaya Batak Angkola untu mengetahui oleh ahli budaya Batak Angkola, (4) penilaian isi materi konseling oleh calon pengguna untuk mengetahui prosedur yang sesuai.

Penilaian yang dilakukan ahli media pembelajaran terhadap keberterimaan produk pengembangan panduan konseling Behavioral berbasis budaya Batak Angkola memiliki indeks rata-rata 0,88 yang mana termasuk dalam kategori tinggi. Dengan demikian, dapat digunakan sebagai panduan untuk konseling dan memiliki keberterimaan terhadap format penulisan dan sampul dalam buku panduan sehingga dapat memudahkan konselor dalam membaca dan menarik. Kemudiam penilaian kesepakatan ahli materi bimbingan dan konseling terhadap keberterimaan produk pengembangan panduan konseling Behavioral berbasis budaya Batak Angkola memiliki indeks rata-rata 0,76 termasuk dalam kategori sedang. Selanjutnya, penilaian ahli budaya Batak Angkola pada aspek kelayakan pada tabel 1 memberikan indeks penilaian 0,96 masuk dalam kategori tinggi. Dengan demikan, produk panduan konseling Behavioral berbasis Batak Angkola layak dalam aspek kelayakan.

Uji keefektifan produk pengembangan dilakukan dengan menggunakan onegroup pretest posttest design. Uji keefektifan produk melibatkan enam orang siswa kelas XI di SMAN 1 Portibi. siswa tersebut terdiri dari tiga siswa laki laki dan tiga siswi perempuan. Keenam siswa yang menjadi sampel yakni EJH, LRD, ADD, NSH, RMS, dan SWH. Keenam siswa dipilih berdasarkan hasil rekomendasi guru BK dan keinginan siswa sendiri. Instrumen pretest menggunakan inventori budaya Batak Angkola yang sudah diuji validitas dan reliabilitasnya. Selisih hasil pretest dan posttest memperlihatkan dampak dari treatment konseling yang diberikan oleh konselor sebagai pengguna. Pada tabel 1 dipaparkan selisih antara pretest dan posttest dari setiap subjek penelitian.

Tabel 1. Selisih Hasil Pretest dan Posttest Subjek Penelitian

\begin{tabular}{ccccc}
\hline Inisial Konseli & Skor Pretest & Skor Posttest & Selisih & Persentase Peningkatan \\
\hline EJH & 115 & 160 & 45 & $13.77 \%$ \\
LRD & 137 & 179 & 42 & $11.22 \%$ \\
ADD & 136 & 171 & 35 & $7.65 \%$ \\
NSH & 121 & 174 & 39 & $9.69 \%$ \\
RMS & 121 & 162 & 31 & $5.61 \%$ \\
SWH & 113 & 169 & 36 & $8.16 \%$ \\
\hline
\end{tabular}

Hasil pretest dan posttest diberikan tindak lanjut dengan analisis wilcoxon untuk mengetahui signifkansi perubahan siswa dari subjek penelitian yang diberikan perlakukan konseling. Pada analisis pengujian wilcoxon ini digunakan jumlah skor prettest dan posttest meaning of life dari setiap siswa subjek penelitian. Pegujian wilcoxon menggunakan aplikasi IBM SPSS Ver 21. Dasar pengambilan keputusan nilai Asymp. Sig (2-tailed) $\leq 0,05$ maka H0 tidak diterima. Sebaliknya, jika nilai Asymp. Sig (2-tailed) $\geq 0,05$, maka $\mathrm{H} 0$ diterima. Pengujian keefektifan pengembangan produk panduan ini memberikan gambaran kelayakan dalam sisi praktis dan secara operasional dapat digunakan. Implementasi produk pada pengujian Wilcoxon menunjukkan bahwa konseling individu sebagai perlakuan yang diberikan berpengaruh terhadap siswa SMA.

\section{PEMBAHASAN}

Format panduan konseling Behavioral bermuatan nilai budaya Batak Angkola didasarkan pada kajian hasil analisis penilaian ahli media pembelajaran dengan hasil penilaian yang didapatkan yaitu data angka dan data verbal. Dari data angka diperoleh dari pengisian instrumen ahli media pembelajaran dengan validasi indeks rata-rata 0,88 termasuk dalam kategori tinggi. Penilaian ahli media pembelajaran ini menunjukkan bahwa panduan ini telah memenuhi unsur kelayakan dari sisi format untuk digunakan sebagai sebuah media pembelajaran bagi guru BK. Dengan demikian, format panduan konseling Behavioral 
berbasis budaya Batak Angkola layak digunakan oleh konselor. Proses penyusunan panduan ini telah mengikuti Pedoman Penulisan Karya Ilmiah Universitas Negeri Malang (2017) dan didasarkan pada PP No. 19/2005 pasal 43 ayat (5); “Tentang kelayakan isi, penyajian, bahasa, dan kegrafikan buku teks pelajaran dinilai oleh BSNP dan ditetapkan dengan Peraturan Menteri". Format panduan yang disusun juga memperhatikan kemenarikan dan kejelasan desain, panduan konseling Behavioral bermuatan nilai budaya Batak Angkola ini memiliki ukuran B5 (18,2 x 25,7cm). Untuk ukuran huruf yang digunakan penulis adalah jenis huruf Arial dengan ukuran font 11 pt yang tampak proporsional dengan ukuran panduan, pemilihan tipe huruf sangat penting karena dapat menambahkan pemahaman dan kejelasan. Desain cover luar buku panduan menggunakan bahan artpaper glossy 210 gram.

Hasil penilaian data angka pengisian instrument ahli bimbingan dan konseling mendapatkan validasi indeks rata-rata 0,76 termasuk dalam kategori sedang. Hasil data verbal yang diberikan oleh ahli bimbingan konseling dan calon pengguna terhadap produk panduan konseling Behavioral bermuatan nilai budaya Batak Angkola didapatkan dari pengisian kolom komentar, saran dan masukan sebagai acuan dalam revisi isi materi panduan. Penilaian objektif ahli ahli bimbingan dan konseling maupun terhadap kelayakan isi materi panduan konseling Behavioral berbasis budaya Batak Angkola ini disusun berdasarkan keberterimaan dengan aspek kegunaan, ketepatan, kelayakan, dan kepatutan. Secara praktis kelayakan isi materi panduan ditunjukkan dari penilaian calon pengguan yaitu guru BK selaku konselor sekolah dengan indeks kategori tinggi, sehingga memberikan penilaian kelayakan isi materi buku panduan konseling ini telah siap digunakan oleh praktisi di sekolah. Bagian isi materi dari panduan konseling bermuatan nilai budaya Batak Angkola ini didasarkan pada kerangka kerja Corey (2017) yang kemudian dimodifikasi dengan memasukkan nilai budaya Batak Angkola.

Penilaian muatan isi nilai budaya Batak Angkola dilakukan oleh ahli budaya Batak Angkola, rangakaian proses penilaian ahli budaya Batak Angkola menghasilkan data angka dan data verbal, data angka dijadikan sebagai landasan dalam kategori kelayakan isi muatan nilai budaya Batak Angkola dan data verbal dijadikan sebagai landasan dalam revisi dan evaluasi panduan. Hasil data angka didapatkan dari instrumen uji ahli dengan hasil validasi indeks rata-rata 0,81 termasuk dalam kategori tinggi. Penilaian secara objektif oleh ahli budaya terhadap isi muatan nilai budaya Batak Angkola berdasarkan aspek kegunaan, ketepatan, dan kejelasan mendapatkan skor indeks dalam kategori tinggi sehingga panduan konseling Behavioral bermuatan nilai budaya Batak Angkola ini dapat digunakan oleh konselor Batak Angkola maupun non Batak Angkola.

Panduan konseling Behavioral bermuatan nilai budaya Batak Angkola ini disusun untuk siswa SMA dengan latar budaya Batak Angkola. Panduan ini diuji cobakan dalam skala terbatas kepada enam orang siswa SMA Negeri 1 Portibi Kabupaten Padang Lawas Utara. Rangkaian uji keefektifan ini menjawab rumusan masalah yang ketiga yaitu keefektifan panduan konseling Behavioral berbasis budaya Batak Angkola. Analisis data pada uji keefektifan ini menggunakan uji statistik non-parametric yaitu Wilcoxon signed test. Berdasarkan hasil output Test Statistics menunjukkan Z hitung sebesar - 2.207b dan nilai Asymp. Sig. (2-tailed) $0,003 \leq$ taraf 0,05. Berdasarkan hasil analsis bahwa 0,003 $\leq$ taraf 0,05 terdapat perbedaan signifikan pada pengujian rata-rata Pretest dan Posttest sehingga dinyatakan panduan konseling Behavioral bermuatan nilai budaya Batak Angkola efektif untuk siswa SMA. Hasil keefektifan penggunanaan panduan konseling Behavioral berbasis budaya Batak Angkola ini terlihat dari selisih hasil pretest dan posttest dengan subjek, antara lain (1) EJH memiliki selisih peningkatan 55 skor, (2) LRD memiliki selisih peningkatan skor 42, (3) ADD memiliki selisih peningkatan skor 35, (4) NSH memiliki selisih peningkatan skor 39, (5) RMS memiliki selisih peningkatan skor 31, dan (6) SWH memiliki selisih peningkatan skor 45. Peningkatan hasil selisih pretest dan posttest ini menunjukkan bahwa panduan konseling Behavioral ini efektif dalam pengembangan diri siswa SMA dengan latar budaya Batak Angkola.

Produk pengembangan panduan konseling Behavioral bermuatan nilai budaya Batak Angkola ini telah dikembangkan dan didapatkan kelayakan baik secara teoritis maupun praktis. Pendekatan konseling Behavioral dikembangkan berdasarkan budaya Batak Angkola dan memilki dasar teoritis dari beberapa hasil penelitian maupun kajian literatur budaya. Karakteristik suku Batak Angkola yang behavioristik disesuaikan dengan pendekatan Behavioral, pertimbangan lainnya adalah makna yang terkandung dalam Nasehat Batak Angkola yaitu Poda na lima (lima pesan) serta sistem kekerabatan Batak Angkola yang menjunjung tinggi Dalihan Na Tolu yakni mengajarkan kita berperilaku dan menghargai orang lain berdasarkan tutur (sapaan). Pribahasa Batak Angkola Hombar adat dohot Ugamo yang menjadi dasar dalam menjalani hidupnya sehari-hari yaitu dalam kehidupan sehari hari harus sejalan dengan adat dan tidak bertentangan dengan ajaran agama. Quinn (Quinn \& Earnshaw, 2013) menjelaskan bahwa intervensi budaya dapat memunculkan rasa hormat terhadap konseli dan memahami tentang nilai-nilai yang dimiliki yang berkaitan dengan fungsi mental, fisik, adat, dan keluarga dalam ruang lingkup budaya. Konseling Behavioral yang telah modifikasi dengan muatan Batak Angkola digunakan dalam membantu siswa. Konselor mempunyai tujuan untuk menyiapkan konseli dengan cara memperhatikan hubungan sehingga merasa nyaman, responsif, dan peduli dalam memfasilitasi eksplorasi, pertumbuhan, dan penggarahan dirinya (Watson, Goldman, \& Greenberg, 2011).

Kelayakan produk yang dikembangkan juga didasarkan pada hasil penelitian-penelitian sebelumnya. Hidayah (2018a) telah mengembangkan teknik modelling berbasis kearifan lokal di Jawa Timur. Salah satu modifikasi teknik modeling dalam penelitian Hidayah (2018b) adalah memfokuskan model pada significant others yang dimiliki siswa. Adanya muatan nilai budaya menjadikan proses konseling yang diberikan sesuai dengan nilai-nilai yang dimiliki konseli. Integrasi dan pemuatan nilai nilai budaya Batak Angkola sebagai basis dalam konseling Behavioral juga merupakan bentuk penyesuaian budaya Indonesia yang kolektivis dengan konstruk konseling Behavioral. Budaya kolektivis merupakan budaya yang sangat mengutamakan peran kelompok dan menjaga harmoni (LeFebvre \& Franke, 2013). Batak Angkola sebagai salah satu budaya 
kolektivis turut mengutamakan harmoni dalam kehidupan masyarakatnya. Individu dengan budaya kolektivis akan memiliki interdependence sehingga memandang dirinya berkaitan dan berhubungan dengan orang lain (Cross, Hardin, \& Gercek-Swing, 2011). Kondisi ini akan menentukan bagaimana arah perilaku yang akan dimunculkan oleh individu.

Kolektivitas masyarakat Batak Angkola akan menjadi objektivitas yang berpengaruh pada penerimaan perilaku individu (Mori \& Hayashi, 2006). Hal ini juga berlaku pada perilaku individu hasil dari proses konseling behavioral. Dengan demikian, integrasi nilai budaya Batak Angkola akan membantu individu untuk menemukan pemecahan masalah yang sesuai dengan nilai masyarakatnya. Hal ini diperlukan karena proses konseling yang efektif akan menghasilkan pemecahan masalah yang diterima oleh masyarakat dan budaya (culturally acceptible) (Hinton \& Patel, 2017; Nicolas et al., 2009).

\section{SIMPULAN}

Berdasaran hasil Kajian-kajian yang telah dipaparkan memberikan simpulan akhir pada penelitian dan pengembangan panduan konseling Behavioral berbasis budaya Batak Angkola. Maka, produk panduan konseling Behavioral bermuatan nilai budaya Batak Angkola yang telah dikembangkan dan memenuhi unsur kelayakan format panduan, yakni kelayakan sistematika penyajian, penulisan, dan kegrafikan. Kelayakan format ini menunjukkan bahwa panduan konseling Behavioral bermuatan nilai budaya Batak Angkola telah layak digunakan sebagai media pembelajaran bagi konselor.

Pengembangan panduan konseling Behavioral bermuatan nilai budaya Batak Angkola ini dilakukan melalui uji efektivitas yang terbatas. Beberapa sekolah lain dan daerah tertentu di wilayah Sumatera utara atau Sub suku Batak lainnya memiliki latar belakang nilai yang berbeda. Sehingga sangat dimungkinkan perbedaan keefektifan dari panduan konseling Behavioral berbasis Batak untuk siswa SMA. Saran dari peneliti diharapkan adanya variabel lain yang muncul dalam pengembangan penelitian budaya Batak Angkola sehingga menambah tentang literatur-literatur tentang budaya Batak Angkola. Peneliti selanjutnya dapat melakukan pengembangan lebih lanjut terkait dengan variabel Behavioral bermuatan nilai budaya Batak Angkola pada konteks lainnya untuk menghadirkan konteks modifikasi yang beragam dari konseling Behavioral.

\section{DAFTAR RUJUKAN}

Corey, G. (2017). Theory and Practice of Counseling and Psychotherapy (Tenth edition). Boston, MA: Cengage Learning.

Cross, S. E., Hardin, E. E., \& Gercek-Swing, B. (2011). The What, How, Why, and Where of Self-Construal. Personality and Social Psychology Review, 15(2), 142-179.

Fitrah, Y. (2008). Warna Lokal Batak Angkola dalam Novel “Azab dan Sengsara” Karya Merari Siregar. Makara, Sosial Humaniora, 12(1), 21-26.

Hanafi, H., Hidayah, N., \& Mappiare, A. (2018). Adopsi Nilai Budaya Osing Dalam Kerangka Meaning of Life. Jurnal Pendidikan: Teori, Penelitian, dan Pengembangan, 3(9), 1237-1243.

Harahap, B. H., \& Siahaan, H. M. (1987). Orientasi Nilai Nilai Budaya Batak. Jakarta: Sanggar Willem Iskandar.

Hidayah, N., \& Ramli, M. (2017). Need of Cognitive-Behavior Counseling Model Based on Local Wisdom to Improve Meaning of Life of Madurese Culture Junior High School Students. Advances in Social Science, Education and Humanities Research, 128 ( $3^{\text {rd }}$ International Conference on Education and Training (ICET 2017)), 301-307. Atlantis Press.

Hidayah, N., Ramli, M., \& Hanafi, H. (2017). Urgency Cognitive-Behavioral Counseling Based on Local Wisdom for Junior High School Counselor in East Java. Advances in Social Science, Education and Humanities Research, Volume 118. Proceedings of the $9^{\text {th }}$ International Conference for Science Educators and Teachers (ICSET 2017), 923-928.

Hidayah, N., Ramli, M., \& Hanafi, H. (2018a). East Java Modeling Techniques to Improve Student Meaning of Life. Advances in Social Science, Education and Humanities Research, Volume 269. Proceedings of the 3rd International Conference on Educational Management and Administration (CoEMA 2018), 181-185.

Hidayah, N., Ramli, M., \& Hanafi, H. (2018b). Modeling Technique on Madurese Culture Based on Bhupa' Bhabu' Ghuru Rato' Values. Advances in Social Science, Education and Humanities Research, Volume 285. International Conference on Education and Technology (ICET 2018), 245-248. Atlantis Press.

Hinton, D. E., \& Patel, A. (2017). Cultural Adaptations of Cognitive Behavioral Therapy. Psychiatric Clinics of North America, 40(4), 701-714.

LeFebvre, R., \& Franke, V. (2013). Culture Matters: Individualism vs. Collectivism in Conflict Decision-Making. Societies, $3(1), 128-146$.

Mori, J., \& Hayashi, M. (2006). The achievement of Intersubjectivity Through Embodied Completions: A Study of Interactions Between First and Second Language Speakers. Applied Linguistics, 27(2), 195-219.

Nicolas, G., Arntz, D. L., Hirsch, B., \& Schmiedigen, A. (2009). Cultural Adaptation of a Group Treatment for Haitian American Adolescents. Professional Psychology: Research and Practice, 40(4), 378-384.

Quinn, D. M., \& Earnshaw, V. A. (2013). Concealable Stigmatized Identities and Psychological Well-Being. Social and Personality Psychology Compass, 7(1), 40-51.

Siahaan, N. (1964). Sedjarah Kebudayaan Batak: Suatu Studi tentang Batak Toba Angkola, Mandailing, Simalungun, Pakpak Dairi, Karo. Medan: CV. Napitupulu. 
224 Jurnal Pendidikan, Vol. 5, No. 2, Bln Februari, Thn 2020, Hal 219-224

Watson, J. C., Goldman, R. N., \& Greenberg, L. (2011). Contrasting Two Clients in Emotion-Focused Therapy for Depression 1: The case of "Tom"; "Trapped in the tunnel". Pragmatic Case Studies in Psychotherapy, 7(2), 268-304. 